\title{
Strepchazolins A and B: Two New Alkaloids from a Marine Streptomyces chartreusis NA02069
}

\author{
Cheng-Long Yang ${ }^{1}$, Yi-Shuang Wang ${ }^{1}$, Cheng-Li Liu ${ }^{1}$, Ying-Jie Zeng ${ }^{1}$, Ping Cheng ${ }^{1}$, \\ Rui-Hua Jiao ${ }^{1}$, Shi-Xiang Bao ${ }^{3}$, Hui-Qin Huang ${ }^{3, *}$, Ren-Xiang Tan ${ }^{1,2, *}$ and Hui-Ming Ge ${ }^{1, *}$ \\ 1 State Key Laboratory of Pharmaceutical Biotechnology, Institute of Functional Biomolecules, \\ School of Life Sciences, Nanjing University, Nanjing 210023, China; yangchenglong1022@163.com (C.-L.Y.); \\ 13529110064@163.com (Y.-S.W.); wendyliuc1@163.com (C.-L.L.); 18013966315@163.com (Y.-J.Z.); \\ chengp1209@126.com (P.C.); rhjiao@nju.edu.cn (R.-H.J.) \\ 2 State Key Laboratory Cultivation Base for TCM Quality and Efficacy, Nanjing University of Chinese Medicine, \\ Nanjing 210023, China \\ 3 Key Laboratory of Biology and Genetic Resources of Tropical Crops of Ministry of Agriculture, \\ Institute of Tropical Biosciences and Biotechnology, Chinese Academy of Tropical Agricultural Sciences, \\ Haikou 571101, China; baoshixiang@itbb.org.cn \\ * Correspondence: huanghq21@163.com (H.-Q.H.); rxtan@nju.edu.cn (R.-X.T.); hmge@nju.edu.cn (H.-M.G.)
}

Academic Editors: Dong-Chan Oh and Sang-Jip Nam

Received: 11 July 2017; Accepted: 27 July 2017; Published: 2 August 2017

\begin{abstract}
Two new alkaloids, strepchazolins A (1) and B (2), together with a previously reported compound, streptazolin (3), were isolated from a marine actinomycete, Streptomyces chartreusis NA02069, collected in the Coast of Hainan Island, China. The structures of new compounds were determined by extensive NMR, mass spectroscopic and X-ray crystallographic analysis, as well as modified Mosher's method. Compound 1 showed weak anti-Bacillus subtilis activity with the MIC value of $64.0 \mu \mathrm{M}$, and weak inhibitory activity against acetylcholinesterase (AChE) in vitro with $\mathrm{IC}_{50}$ value of $50.6 \mu \mathrm{M}$, while its diastereoisomer, Compound 2 , is almost inactive.
\end{abstract}

Keywords: alkaloid; strepchazolin; streptazolin; Streptomyces charteus; marine natural product; antimicrobial activity; acetylcholinesterase inhibitory activity

\section{Introduction}

Research conducted over the past several decades in marine microorganisms has clearly indicated that the ocean is a great resource of microorganisms for producing structurally diverse and biologically active secondary metabolites due to their unique environment [1]. Among all known microbes, the filamentous bacteria in the order Actinomycetales are considered as the most prolific source for producing secondary metabolites [2-4], consisting of unusual polyketides, nonribosomal peptides, terpenoids, alkaloids, lipids and others. For instance, marinomycins A-D were isolated from a marine sediment culture of Marinispora sp. CNQ-140 showing significant antibacterial activities against drug-resistant pathogens, and selective cancer cell cytotoxicities against six melanoma cell lines [5]. Lajollamycins, a family of nitro group-bearing spiro- $\beta$-lactone- $\gamma$-lactams were produced by a marine-derived Streptomyces sp. [6]. Salinosporamide, a potent proteasome inhibitor with an unusal $\beta$-lactone moiety isolated from a marine Salinospora tropica has been entered human clinical trial for the treatment of multiple myeloma [7]. In our search for new bioactive compounds from marine microorganisms, we isolated actinomycete strains from a marine sediment sample in the Coast of Hainan Island of China. During the screening, we found one of the isolated strains, NA02069, was designated as Streptomyces chartreusis based on its 16s rDNA sequence. S. chartreusis has been previously reported to produce chartreusin, chrymutasins, and calcimycin [8,9], all of which belong 
to the family of polyketides. In order to enrich the diversity of the compounds from this strain, we became interested in S. chartreusis NA02069 to find whether different compounds can be produced. In this study, we report the isolation and structure elucidation of two new (1) and (2) and a known (3) alkaloid compounds (Figure 1). Compounds 1 and $\mathbf{2}$ were evaluated for their antimicrobial and acetylcholinesterase inhibitory activities.

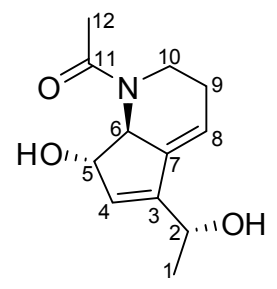

1

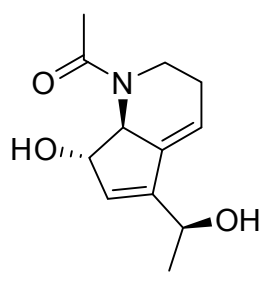

2

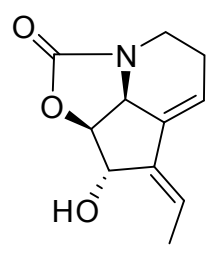

3

Figure 1. Structure of compounds (1-3) isolated from S. chartreusis NA02069.

\section{Results}

\subsection{Taxonomy and Phylogenetic Analysis of the Strain NA02069}

The 16s rDNA sequence of strain NA02069 was amplified by polymerase chain reaction (PCR) and sequenced. After alignment analysis using Basic Logic Alignment Search Tool (BLAST), strain NA02069 showed 100\% identities (1352 bp) to a subclade, which also included the type strains of Streptomyces chartreusis ISP 5085, S. chartreusis DA10203, and S. chartreusis NBRC 12753 (Figure 2). Thus, the strain was assgined as Streptomyces chartreusis NA02069 [10].

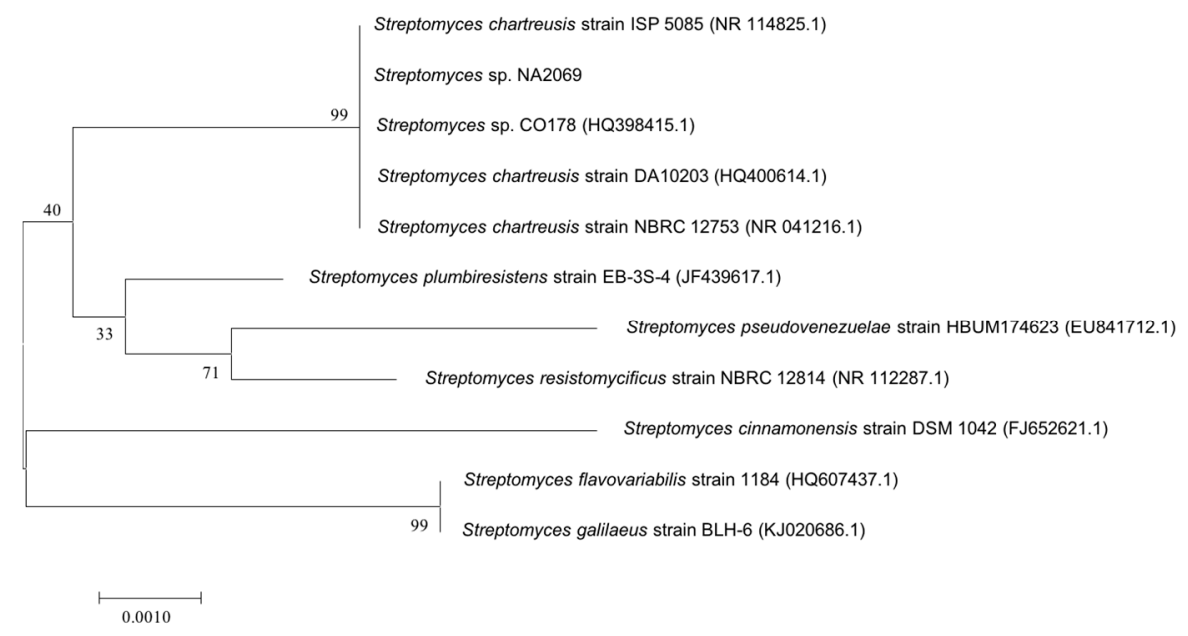

Figure 2. Neighbor-joining tree based on 16s rDNA sequence of strain NA02069.

\subsection{Isolation and Structure Elucidation}

The actinomycete strain was cultured at $28{ }^{\circ} \mathrm{C}$ with $130 \mathrm{rpm}$ agitation in YEME medium $(20 \mathrm{~L})$ medium. After 10 days, the filtrate of the fermented culture broth was extracted repeatedly with ethyl acetate three times to afford a brown crude extract, which was subjected to repeated column chromatography (CC) over silica-gel, Sephadex LH-20, octadecylsilane (ODS) and high performance liquid chromatography (HPLC) to yield two new alkaloids, strepchazolins A (1), B (2), and a known Compound (3). The known compound was identified as streptazolin by comparison of their spectroscopic data with those in the literature [11].

Strepchazolin A (1) was obtained as a pale yellow crystal. Its molecular formula was determined as $\mathrm{C}_{12} \mathrm{H}_{17} \mathrm{NO}_{3}$ on the basis of the sodium-adduct high-resolution ESIMS ion at $m / z 246.1116[\mathrm{M}+\mathrm{Na}]^{+}$, 
(calcd for $\mathrm{C}_{12} \mathrm{H}_{17} \mathrm{NO}_{3} \mathrm{Na}$, 246.1101) along with the ${ }^{13} \mathrm{C}$ NMR data (Table 1). The ${ }^{1} \mathrm{H}$ NMR spectrum of 1 in methanol- $d_{4}$ displayed two double-bond protons $\left(\delta_{\mathrm{H}} 5.85\right.$ and 6.05), three oxygen/nitrogen substituted methine protons $\left(\delta_{\mathrm{H}} 4.51,4.56\right.$, and 4.31$)$, four methylene protons $\left(\delta_{\mathrm{H}} 3.16,3.83,2.30\right.$ and $2.30)$, and six methyl protons in two methyl groups $\left(\delta_{\mathrm{H}} 1.38\right.$ and 2.19). The ${ }^{13} \mathrm{C}$ NMR spectrum showed one carbonyl carbon $\left(\delta_{C} 175.4\right)$, four resonances in the double bond region $\left(\delta_{C} 148.5,140.7,130.3\right.$, and $117.8)$, three oxygen/nitrogen substituted carbons $\left(\delta_{C} 81.0,68.4\right.$, and 64.7), and four sp ${ }^{3}$-hybrized quaternary carbons $\left(\delta_{\mathrm{C}} 46.2,25.8,22.8\right.$, and 22.6). Further analysis of its HSQC spectrum assigned all signals for ${ }^{1} \mathrm{H}_{-}{ }^{13} \mathrm{C}$ one bond correlations. The ${ }^{1} \mathrm{H}-{ }^{1} \mathrm{H}$ COSY spectrum of $\mathrm{H}-1\left(\delta_{\mathrm{H}} 1.38\right) / \mathrm{H}-2\left(\delta_{\mathrm{H}} 4.51\right)$; $\mathrm{H}-4\left(\delta_{\mathrm{H}} 5.85\right) / \mathrm{H}-5\left(\delta_{\mathrm{H}} 4.56\right) / \mathrm{H}-6\left(\delta_{\mathrm{H}} 4.31\right)$; and $\mathrm{H}-8\left(\delta_{\mathrm{H}} 6.05\right) / \mathrm{H}-9\left(\delta_{\mathrm{H}} 2.30\right) / \mathrm{H}-10\left(\delta_{\mathrm{H}} 3.16\right.$ and 3.83$)$ revealed three spin systems are present in 1 (Figure 3). The HMBC correlations of H-1/C-3, H-2/C-4, H-6/C-8, H-9/C-7 suggested the above three spin systems were connected through C-2-C-3-C-4, and C-6-C-7-C-8, respectively. Moreover, the HMBC correlations of H-2/C-7, H-4/C-7, as well as H-8/C-3 revealed the connectivity between C-3-C-7, revealing the presence of a cyclopentene moiety. The HMBC correlations of H-6/C-8 and H-10/C-8 together with their typical nitrogen substituted chemical shifts for $\delta_{\mathrm{C}-6} 68.4 / \delta_{\mathrm{H}-6} 4.31$ and $\delta_{\mathrm{C}-10} 46.2 / \delta_{\mathrm{H}-10 \mathrm{a}} 3.83$ and $\delta_{\mathrm{H}-10 \mathrm{~b}} 3.16$ indicated the presence of a tetrahydropyridine moiety. Finally, the HMBC correlation of H-10 and H-12 with carbonyl carbon $\mathrm{C}-11$ revealing that an acetyl group was anchored at the $\mathrm{N}$-atom. The remaining two hydroxyl groups were connected at C-2 $\left(\delta_{C} 64.7\right)$ and $C-5\left(\delta_{C} 81.0\right)$ on the basis of their chemical shifts. Thus, the planar structure of 1 was established.

Table 1. ${ }^{1} \mathrm{H}$ and ${ }^{13} \mathrm{C}$ NMR (600 and $150 \mathrm{MHz}$ in methanol- $\left.d_{4}\right)$ data for compounds $\mathbf{1}$ and 2.

\begin{tabular}{ccccc}
\hline & \multicolumn{3}{c}{$\mathbf{1}$} & \multicolumn{2}{c}{$\mathbf{2}$} \\
\cline { 2 - 5 } No. & $\delta \mathbf{c}$, Type & $\delta_{\mathbf{H}}(\boldsymbol{J}$ in Hz) & $\delta_{\mathrm{C}}$, Type & $\delta_{\mathbf{H}}(\boldsymbol{J}$ in Hz) \\
\hline 1 & $22.6, \mathrm{CH}_{3}$ & $1.38, \mathrm{~d}(6.5)$ & $22.7, \mathrm{CH}_{3}$ & $1.36, \mathrm{~d}(6.5)$ \\
2 & $64.7, \mathrm{CH}$ & $4.51, \mathrm{q}(6.5)$ & $64.8, \mathrm{CH}$ & $4.55, \mathrm{q}(6.5)$ \\
3 & $148.5, \mathrm{C}$ & & $149.2, \mathrm{C}$ & \\
4 & $130.3, \mathrm{CH}$ & $5.85, \mathrm{brs}$ & $129.0, \mathrm{CH}$ & $5.86, \mathrm{brs}$ \\
5 & $81.0, \mathrm{CH}$ & $4.56, \mathrm{~m}$ & $81.0, \mathrm{CH}$ & $4.56, \mathrm{~m}$ \\
6 & $68.4, \mathrm{CH}$ & $4.31, \mathrm{brs}$ & $68.4, \mathrm{CH}$ & $4.30, \mathrm{brs}$ \\
7 & $140.7, \mathrm{C}$ & & $140.9, \mathrm{C}$ & \\
8 & $117.8, \mathrm{CH}$ & $6.05, \mathrm{~m}$ & $117.2, \mathrm{CH}$ & $5.96, \mathrm{~m}$ \\
9 & $25.8, \mathrm{CH} \mathrm{H}_{2}$ & $2.30, \mathrm{~m}$ & $25.8, \mathrm{CH}_{2}$ & $2.30, \mathrm{~m}$ \\
10 & $46.2, \mathrm{CH}_{2}$ & $3.16, \mathrm{td}(12.2,2.9)$ & $46.2, \mathrm{CH}_{2}$ & $3.16, \mathrm{td}(12.2,2.9)$ \\
& & $3.83, \mathrm{dt}(12.2,2.9)$ & & $3.83, \mathrm{dt}(12.2,2.9)$ \\
11 & $175.4, \mathrm{C}$ & & $175.4, \mathrm{C}$ & \\
12 & $22.8, \mathrm{CH}_{3}$ & $2.19, \mathrm{~s}$ & $22.8, \mathrm{CH}_{3}$ & $2.20, \mathrm{~s}$ \\
\hline
\end{tabular}

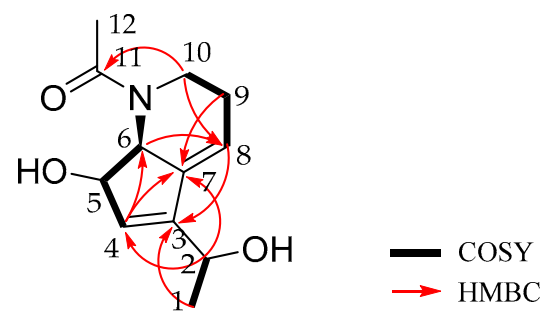

Figure 3. The Key 2D NMR correlations of 1 .

The full structure and absolute configurations at all chiral centers of 1 were assigned based on the X-ray crystallographic analysis. A high-quality single crystal was obtained from slow evaporation of compound $\mathbf{1}$ in acetone/MeOH solutions at low temperature. The X-ray crystallography data measured in a $\mathrm{Cu} \mathrm{K} \alpha$ radiation in low temperature fully confirmed the proposed structure and determined the absolute configuration of $\mathbf{1}$ as $2 R, 5 S$, and $6 S$ (Figure 4). 


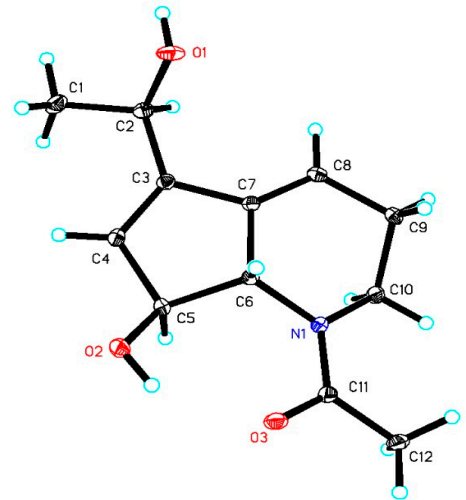

Figure 4. X-ray crystal structure of compound 1.

Strepchazolin B (2) was obtained as a pale yellow oil, which analyzed for the same molecular formula, $\mathrm{C}_{12} \mathrm{H}_{17} \mathrm{NO}_{3}$, as 1 by HRESIMS (obsd [M Na] ${ }^{+}$at $m / z 246.1103$, calcd for $\mathrm{C}_{12} \mathrm{H}_{17} \mathrm{NO}_{3} \mathrm{Na}$ 246.1101) in combination with interpretation of ${ }^{1} \mathrm{H}$ and ${ }^{13} \mathrm{C}$ NMR data (Table 1). The ${ }^{13} \mathrm{C}$ NMR data of $\mathbf{2}$ were almost identical to those of $\mathbf{1}$, however the ${ }^{1} \mathrm{H}$ NMR spectra between $\mathbf{1}$ and $\mathbf{2}$ were slightly different (Figure S17). Further interpretation of HSQC, HMBC and ${ }^{1} \mathrm{H}-{ }^{1} \mathrm{H}$ COSY spectral data (Figure 5) of $\mathbf{2}$ established that the planar structure of compound $\mathbf{2}$ is identical to that of $\mathbf{1}$.
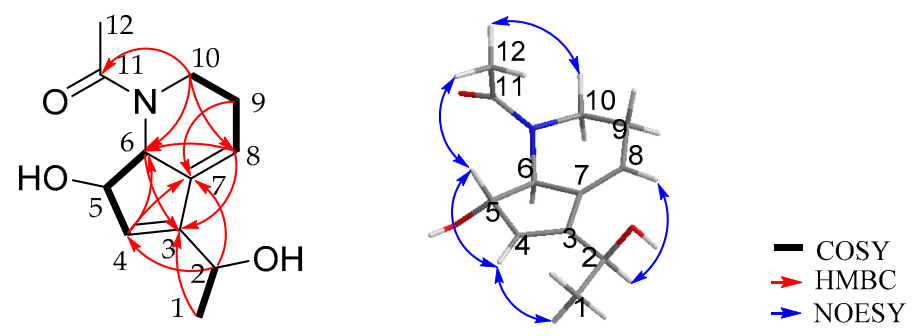

Figure 5. The Key 2D NMR correlaitons of 2.

In the NOESY spectrum of 2 (Figure 5), the NOE correlation between H-5 and H-12 demonstrated that $\mathrm{H}-5$ and $\mathrm{H}-6$ possessed $\beta$ and $\alpha$-orientations, respectively, consistent with those observed in 1. The chemical shifts for H-5/C-5 and H-6/C-6 in 2 are the same with those in 1, which suggest configurations of C-5 and C- 6 in $\mathbf{2}$ are the same to 1 . The absolute configuration of C-2 in compound 2 was determined by a modified Mosher's method [12,13]. Using low temperature control of the esterify reaction (MTPA-Cl/pyridine), we were able to regioselectively esterified the $\mathrm{C}-2$ hydroxyl group in 2. The ${ }^{1} \mathrm{H}$ chemical shifts of $\mathbf{2 a}$ and $\mathbf{2} \mathbf{b}$ were assigned by analyzing their $\mathrm{HSQC}$ and ${ }^{1} \mathrm{H}-{ }^{1} \mathrm{H}$ COSY NMR spectra. The $\Delta \delta$ values between $(S)$ and (R)-MTPA esters demonstrated that C-2 possessed an $S$-configuration (Figure 6), which is opposite to that in compound $\mathbf{1}$ as expected.

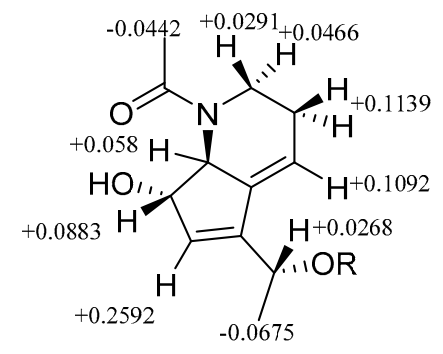

2a $\mathrm{R}=(S)$-MTPA

2b $\mathrm{R}=(R)-\mathrm{MTPA}$

Figure 6. ${ }^{1} \mathrm{H}$ NMR $\Delta \delta_{S-R}$ values in ppm between the (S)- and (R)-MTPA esters $\mathbf{2 a}$ and $\mathbf{2 b}$ in methanol- $d_{4}$. 


\subsection{Bioactivities of Strepchazolins}

As a primary screen for antibacterial and acetylcholinesterase inhibitory activities, the results were shown in Tables 2 and 3. Compound $\mathbf{1}$ exhibited weak antibacterial activity against Bacillus subtilis with its MIC value of $64.0 \mu \mathrm{M}$, and weak acetylcholinesterase inhibitory activity with IC $_{50}$ value of $50.6 \mu \mathrm{M}$. However, compound $\mathbf{2}$, the diastereoisomer of $\mathbf{1}$, is almost inactive (Tables 2 and 3).

Table 2. The antimicrobial MIC ( $\mu \mathrm{M})$ of compounds $\mathbf{1}$ and 2.

\begin{tabular}{cccc}
\hline & $\mathbf{1}$ & $\mathbf{2}$ & Rifampicin \\
\hline Bacillus subtilis & 64.0 & $>128.0$ & 1.0 \\
\hline
\end{tabular}

Table 3. In vitro acetylcholinesterase (AChE) inhibitory activity of compounds $\mathbf{1}$ and $\mathbf{2}$.

\begin{tabular}{cccc}
\hline Compound & $\mathbf{1}$ & $\mathbf{2}$ & Huperzine A \\
\hline $\mathrm{IC}_{50}(\mu \mathrm{M})$ & 50.6 & $>100.0$ & 4.3 \\
\hline
\end{tabular}

\section{Experimental Section}

\subsection{General Methods}

Optical rotation was measured in $\mathrm{MeOH}$ on a Rudolph Research Analytical Autopol IV automatic polarimeter. Mass spectra were acquired on an Agilent 6250 TOF LC-MS instrument equipped with an electrospray ionization (ESI) probe operating in positive-ion mode with direct infusion. NMR experiments were accomplished in Methanol- $d_{4}$ on a Bruker DRX-600 spectrometer with ${ }^{1} \mathrm{H}$ and ${ }^{13} \mathrm{C}$ nuclei observed at 600 and $150 \mathrm{MHz}$, respectively, with TMS or solvent signal adopted as internal standards. Silica gel (200-300 mesh) for CC (column chromatography) and GF254 (10-20 $\mu \mathrm{m})$ for TLC (thin layer chromatography) were purchased from Qingdao Marine Chemical Company, China. Sephadex LH-20 were purchased from GE Biotech, USA. Semi-preparative reverse phase-high performance liquid chromatography (RP-HPLCs) were accomplished on an Eclipse XDB-C18 column $(5 \mu \mathrm{M}, 250 \times 9.4 \mathrm{~mm})$ from Agilent Technologies Inc. USA (Santa Clara, CA, USA). All chemicals used in the study were of analytical grade and HPLC grade.

\subsection{Strain Isolation and Cultivation}

S. chartreusis NA02069 was isolated from a sediment from the coast of Hainan Island, China. The purified strain was cultured in modified $38^{\#}$ medium plate (consisting $4 \mathrm{~g}$ yeast extract, $4 \mathrm{~g}$ glucose, $5 \mathrm{~g}$ malt extract, $1 \mathrm{~mL}$ multi-vitamins, $20 \mathrm{~g}$ agar, $27 \mathrm{~g}$ sea salt in $1 \mathrm{~L}$ water) at $28{ }^{\circ} \mathrm{C}$ for 4 days. After 2 days of incubation in 10 flasks each containing $100 \mathrm{~mL}$ Tryptone Soya Broth medium (Weigh $30 \mathrm{~g}$ to $1 \mathrm{~L}$ of water) at $28^{\circ} \mathrm{C}$ with $130 \mathrm{rpm}$ agitation, the seed cultures were used to inoculate 100 flasks each containing $200 \mathrm{~mL}$ YEME medium (consisting $4 \mathrm{~g}$ yeast extract, $4 \mathrm{~g}$ glucose, $10 \mathrm{~g}$ malt extract, $27 \mathrm{~g}$ sea salt in $1 \mathrm{~L}$ water).

\subsection{Isolation of Compounds $\mathbf{1}, \mathbf{2}$ and $\mathbf{3}$}

After 10 days cultivation, the filtrate $(20 \mathrm{~L})$ of the fermented culture broth was extracted three times using ethyl acetate. The organic extract was enriched in vacuo to yield $3.2 \mathrm{~g}$ of a brown thick oil material. The extract was subjected to column chromatography (CC) over silica gel fractionated with $500 \mathrm{~mL}$ mixtures of petroleum ether-ethyl acetate $(v / v, 100: 0,100: 2,100: 4,100: 10,100: 50,0: 100)$, $\mathrm{CH}_{2} \mathrm{Cl}_{2}-\mathrm{MeOH}(v / v, 100: 0,100: 2,100: 4,100: 10,100: 50,0: 100)$ to afford 17 fractions (04-1 $\rightarrow$ 04-17 collected according to TLC monitoring). 04-5 (0.5 g) was subsequently separated by ODS chromatography with $\mathrm{H}_{2} \mathrm{O}-\mathrm{MeOH}(v / v, 70: 30,60: 40,50: 50,40: 60,30: 70,0: 100)$ to afford 8 fractions (04-5-1 $\rightarrow 04-5-8$ collected according to TLC monitorings). Finally, compounds $\mathbf{1}(11.2 \mathrm{mg}), 2$ (9.4 mg), 3 (6.7 $\mathrm{mg}$ ) were eluted as 
pure compounds using semi-preparative reverse-phase HPLC $\left(2 \mathrm{~mL} / \mathrm{min}\right.$, detector $\mathrm{UV} \lambda_{\max } 254 \mathrm{~nm}$, $\left.\mathrm{MeOH} / \mathrm{H}_{2} \mathrm{O} 38: 62\right)$.

Compound 1: Pale yellow crystal; $[\alpha]_{D}^{25}-68^{\circ}$ (c 0.10, MeOH); m.p.: $125-126{ }^{\circ} \mathrm{C}$; UV (MeOH) $\lambda_{\max }$ ( $\log \varepsilon): 217$ (0.791), $281(0.391) \mathrm{nm}$. HR-ESI-MS $(\mathrm{m} / z)$ : 246.1116 [M $+\mathrm{Na}]^{+}$(calcd. for $\mathrm{C}_{12} \mathrm{H}_{17} \mathrm{NO}_{3} \mathrm{Na}$, 246.1101); ${ }^{1} \mathrm{H}$ and ${ }^{13} \mathrm{C}$ NMR data are listed in Table 1.

Compound 2: pale yellow oil; $[\alpha]_{D}^{25}-26^{\circ}(c 0.1, \mathrm{MeOH}) ; \mathrm{UV}(\mathrm{MeOH}) \lambda_{\max }(\log \varepsilon)$ : $217(0.714), 281(0.224)$ nm. HR-ESI-MS ( $/ \mathrm{z} / z)$ : 246.1103 [M + Na] ${ }^{+}$(calcd. for $\mathrm{C}_{12} \mathrm{H}_{17} \mathrm{NO}_{3} \mathrm{Na}, 246.1101$ ); ${ }^{1} \mathrm{H}$ and ${ }^{13} \mathrm{C}$ NMR data are listed in Table 1.

\subsection{Crystal Data of $\mathbf{1}$}

Crystal data of compound 1 was collected on an Agilent Xcalibur Nova single-crystal diffractometer using $\mathrm{Cu} \mathrm{K} \alpha$ radiation in low temperature. The structures were solved by direct methods using SHELXS-97 and refined by means of full-matrix least squares. Crystal data of compound 1 have been deposited with the Cambridge Crystallographic Data Centre as supplementary publication CCDC 1557150.

Crystal data for 1: molecular formula $\mathrm{C}_{12} \mathrm{H}_{17} \mathrm{NO}_{3}, M_{\mathrm{r}}=223.26$, monoclinic crystals, $a=4.37020$ (10) $\AA$, $b=14.0896$ (4) $\AA, c=9.1364$ (2) $\AA, Z=2, \mu=0.779 \mathrm{~mm}^{-1}$ and $F(000)=240$; Crystal dimensions: $0.180 \times 0.150 \times 0.100 \mathrm{~mm}^{3}$, Volume $=558.42(2) \AA^{3}, R$ (reflections) $=0.0185$ (1573),$R$ indices $[\mathrm{I}>2 \operatorname{sigma}(\mathrm{I})] R_{1}=0.0278, w R_{2}=0.0739$.

\subsection{Formation of the (S)- and (R)-MTPA Esters of 2}

To a solution of $2(0.3 \mathrm{mg}, 1.3 \mu \mathrm{mol})$ in anhydrous pyridine $(0.15 \mathrm{~mL}),(R)-(-)$-MTPA chloride $(1.6 \mathrm{mg}, 6.5 \mu \mathrm{mol})$ was added, and the reaction mixture was stirred at $0{ }^{\circ} \mathrm{C}$ for $1 \mathrm{~h}$. Methanol $(0.3 \mathrm{~mL})$ was added to the reaction mixture to terminate the reaction. The solvent was evaporated under reduced pressure, and the residue was purified by HPLC using Acetonitrile- $\mathrm{H}_{2} \mathrm{O}(65: 35 \rightarrow 90: 10)$ as the eluent to afford (S)-MTPA ester $2 \mathrm{a}(0.1 \mathrm{mg})$ as a colorless oil. $2(0.3 \mathrm{mg}, 1.3 \mu \mathrm{mol})$ and (S)-(+)-MTPA chloride $(1.6 \mathrm{mg}, 6.5 \mu \mathrm{mol})$ were treated with the same procedure to afford $(R)$-MTPA ester $\mathbf{2 b}(0.1 \mathrm{mg})$ as a colorless oil.

S-MTPA ester (2a): colorless oil; HR-ESI-MS ( $m / z)$ : $462.1486[\mathrm{M}+\mathrm{Na}]^{+}$(calcd. for $\mathrm{C}_{22} \mathrm{H}_{24} \mathrm{~F}_{3} \mathrm{NO}_{5} \mathrm{Na}$, 462.1499); ${ }^{1} \mathrm{H}$ NMR data are listed in Table S1 of Supplementary Materials.

$R$-MTPA ester (2b): colorless oil; HR-ESI-MS $(m / z)$ : $462.1500[\mathrm{M}+\mathrm{Na}]^{+}$(calcd. for $\mathrm{C}_{22} \mathrm{H}_{24} \mathrm{~F}_{3} \mathrm{NO}_{5} \mathrm{Na}$, 462.1499); ${ }^{1} \mathrm{H}$ NMR data are listed in Table S1 of Supplementary Materials.

\subsection{Antibacterial Assay}

Following the described procedure [14], the antibacterial activities of compounds $\mathbf{1}$ and $\mathbf{2}$ were tested in 96-well microplates. The tested bacterial strain, Bacillus subtilis, was preserved in State Key Laboratory of Pharmaceutical Biotechnology, Nanjing University, China. The strain was grow on a MHB solid medium and then cultured $24 \mathrm{~h}$ in liquid medium. The testing system consists of $50 \mu \mathrm{L}$ diluted bacterial solution $(\sim 105 \mathrm{CFU} / \mathrm{mL}), 49 \mu \mathrm{L}$ fresh medium and $1 \mu \mathrm{L}$ tested compound. The microplate was vibrated for homogenizing the mixture and then incubated at $37^{\circ} \mathrm{C}$ for $24 \mathrm{~h}$. MIC (Minimal Inhibitory Concentration) accounts for the magnitude of the antibacterial activity.

\subsection{Bioactivity Assay}

The acetylcholinesterase inhibitory activities were assayed according to a method reported in the literature [15]. Briefly, compounds $\mathbf{1}$ and $\mathbf{2}$ were dissolved in DMSO and diluted to different concentrations using $0.1 \mathrm{M}$ phosphate buffer ( $\mathrm{pH}$ 8.0). The enzymatic reaction was triggered by adding $20 \mu \mathrm{L}$ of $3.33 \mathrm{mM}$ 5,5'-dithio-bis (2-nitrobenzoic acid) (DTNB, Sigma-Aldrich, St. Louis, MO, USA) 
to the reaction system (consisting of $2 \mu \mathrm{L}$ of the tested sample solution, $20 \mu \mathrm{L}$ of $0.35 \mathrm{U} / \mathrm{mL}$ AChE solution and $20 \mu \mathrm{L}$ of $3.33 \mathrm{mM}$ 5,5'-dithio-bis (2-nitrobenzoic acid) (DTNB) and $138 \mu \mathrm{L}$ of phosphate buffer). Reaction substances were detected through Microplate Reader by measuring the absorbance at $410 \mathrm{~nm}$. Meanwhile, Huperzine A and DMSO were used as positive and negative controls, respectively. Each test was performed in triplicate. Then IC $_{50}$ of each compound was calculated by SPSS 16.0 [16].

\section{Conclusions}

In summary, two new alkaloids, strepchazolins A (1) and B (2), as well as a known compound streptazolin (3) were isolated from a marine actinomycete S. chartreusis NA02069. Their structures were determined using a combination of HRESIMS and NMR spectroscopic and X-ray crystallographic data together with modified Mosher's method. Compounds 1 showed weak anti-Bacillus subtilis activity and weak inhibitory activity against acetylcholinesterase, while its diastereoisomer, compound 2, is almost inactive. The research described here further indicates that marine actinomycetes are a rich source for new bioactive natural products that could lead to the discovery of new drugs or drug leads.

Supplementary Materials: The following are available online at www.mdpi.com/1660-3397/15/8/244/s1, Supplementary Materials including HRESIMS spectra, 1D and 2D NMR spectra, tabulated NMR data for 2a and $\mathbf{2 b}$.

Acknowledgments: This study was financially supported by NSFC (nos. 81522042, 21572100, 81421091, 81500059, 81673333, 81673333 and 21672101) SBK2015022152, and Jiangsu Provincial Key Medical Discipline (laboratory) (no. ZDXKA2016020).

Author Contributions: Cheng-Long Yang, Yi-Shuang Wang, Cheng-Li Liu, Ying-Jie Zeng, Ping Cheng, Rui-Hua Jiao, Shi-Xiang Bao, Hui-Qin Huang, Ren-Xiang Tan, and Hui-Ming Ge conceived and designed experiments. Cheng-Long Yang and Yi-Shuang Wang cultured, isolated and characterized the compounds. Cheng-Li Liu and Ping Cheng performed the biological tests. Ying-Jie Zeng performed the phylogenetic analysis of the strain. Shi-Xiang Bao and Hui-Qin Huang isolated the strain. Cheng-Long Yang and Hui-Ming Ge wrote the paper.

Conflicts of Interest: The authors declare no conflict of interest.

\section{References}

1. Xiong, Z.Q.; Wang, J.F.; Hao, Y.Y. Recent advances in the discovery and development of marine microbial natural products. Mar. Drugs 2013, 11, 700-717. [CrossRef] [PubMed]

2. Molinski, T.F.; Dalisay, D.S.; Lievens, S.L.; Saludes, J.P. Drug development from marine natural products. Nat. Rev. Drug Discov. 2009, 8, 69-85. [CrossRef] [PubMed]

3. Bérdy, J. Thoughts and facts about antibiotics: Where we are now and where we are heading. J. Antibiot. 2012, 65, 385-395. [CrossRef] [PubMed]

4. Liu, Y. Renaissance of marine natural product drug discovery and development. J. Mar. Sci. Res. Dev. 2012, 2, e106. [CrossRef]

5. Kwon, H.C.; Kauffman, C.A.; Jensen, P.R.; Fenical, W. Marinomycins A-D, antitumor-antibiotics of a new structure class from a marine actinomycete of the recently discovered genus "Marinispora". J. Am. Chem. Soc. 2006, 128, 1622-1632. [CrossRef] [PubMed]

6. Keebeom, K.; SoHyoung, L.; SeongHwan, K. Lajollamycins, Nitro group-bearing spiro- $\beta$-lactone- $\gamma$-lactams obtained from a marine-derived Streptomyces sp. J. Nat. Prod. 2014, 77, 2099-2104.

7. McGlinchey, R.P.; Nett, M.; Eustaquio, A.S.; Asolkar, R.N.; Fenical, W.; Moore, B.S. Engineered biosynthesis of antiprotealide and other unnatural salinosporamide proteasome inhibitors. J. Am. Chem. Soc. 2008, 130, 7822-7823. [CrossRef] [PubMed]

8. Mal, D.; Patra, A.; Roy, H. Convergent and rapid assembly of benzonaphthopyranone cores of chartreusin, chrymutasins and hayumicins. Cheminform 2005, 36, 7895-7898. [CrossRef]

9. Wu, Q.; Gou, L.; Lin, S. Characterization of the N-methyltransferase CalM involved in calcimycin biosynthesis by Streptomyces chartreusis NRRL 3882. Biochimie 2013, 95, 1487. [CrossRef] [PubMed]

10. Lin, Y.B.; Wang, X.Y.; Wang, T.T. Streptomyces graminifolii sp. nov. isolated from grassland soil. Int. J. Syst. Evol. Microbiol. 2013, 63, 1545. [CrossRef] [PubMed] 
11. Drautz, H.; Zähner, H. Isolation and structure of streptazolin. Helv. Chim. Acta 1981, 64, $1752-1765$. [CrossRef]

12. Felix, F.; Manuel, S.J.; Emilio, Q.; Riguera, R. Determining the absolute stereochemistry of secondary/ secondary diols by ${ }^{1} \mathrm{H}$ NMR: Basis and applications. J. Org. Chem. 2005, 70, 3778-3790.

13. Yamada, T.; Suzue, M.; Arai, T.; Kikuchi, T.; Tanaka, R. Trichodermanins C-E, new diterpenes with a fused 6-5-6-6 ring system produced by a marine sponge-derived fungus. Mar. Drugs 2017, 15, 169. [CrossRef] [PubMed]

14. Di Modugno, E.; Erbetti, I.; Ferrari, L.; Galassi, G.; Hammond, S.M.; Xerri, L. In vitro activity of the Tribactam GV104326 against gram-positive, gram-negative, and anaerobic bacteria. Antimicrob. Agents Chemother. 1994, 38, 2362-2368. [CrossRef] [PubMed]

15. Ellman, G.L.; Courtney, K.D., Jr.; Andres, V.; Featherstone, R.M. A new and rapid colorimetric determination of acetylcholinesterase activity. Biochem. Pharmacol. 1961, 7, 88-90. [CrossRef]

16. Ge, H.M.; Zhu, C.H.; Shi, D.H.; Zhang, L.D.; Xie, D.Q.; Yang, J.; Ng, S.W.; Tan, R.X. Hopeahainol A: An acetylcholinesterase inhibitor from Hopea hainanensis. Chem. Eur. J. 2008, 14, 376-381. [CrossRef] [PubMed]

(C) 2017 by the authors. Licensee MDPI, Basel, Switzerland. This article is an open access article distributed under the terms and conditions of the Creative Commons Attribution (CC BY) license (http://creativecommons.org/licenses/by/4.0/). 